\title{
Implication of Human Capital Development on Economic Growth by Using Cointegration and Error Correction Modelling in Pakistan
}

\author{
Nayab Minhaj \\ Department of Economics, Faculty of Art \& Social Sciences, University of Karachi, Karachi, Sindh, Pakistan \\ E-mail: nayabminhaj@yahoo.com
}

Received: 7 February 2021; Revised: 6 April 2020; Accepted: 26 April 2021

\begin{abstract}
The study examined human capital development and Pakistan economic growth in the quest to evaluate various policy grounds upon which capital development exist among nations and its nexus and effect it will have on the domestic economy, this paper cross-examined the objective purpose of capital development as a measure of economy development the vector error correction approach was adopted as an estimation technique to reveal the short and long term disequilibrium in the study. Findings from the study show that there is a direct influence between the subject matter of human capital and economic growth in Pakistan by these findings, the study recommends that the government of Pakistan should continue the level of spending for the two sectors of health and education which are the underlying sectors for attaining capital development and purposeful growth and development in the Pakistan economy.
\end{abstract}

Keywords: human capital development, government expenditures on education (GEE), government expenditures on health $(\mathrm{GEH})$, economic growth, cointegration, vector error correction model

JEL Codes: C1, H51, H52, H53, H57

\section{Introduction}

The effort made by the human capital formation in stimulating growth in Pakistan's economy and the world can't be overlooked. Economists have recognized human capital formation as a prerequisite for every nation's transformational change in all tiers of the economic and other under-aligned factors. No country has achieved a measurable growth in development economic wise without adequate human capital formation. The human capital formation which is well developed in human capacity focuses on human developments and capabilities, which includes people's skills and knowledge acquired through knowledge gathering using education as a guiding tool, which mainly depends on the value of one's health, nutrition value, and others such as skills. It is also concerned with the effort put in place to gain training through skills as a means of factors of production. Further, human capacity is an effective instrument for economic development as production and therefore profitability is perceived to improve. The further States invest in people (i.e. their schooling, education, and health), the more effective and competitive they can be, and that the principal objectives of growth are health and education for certain nations. These indexes are vital and serve as the total close of an era. Basic wellbeing is central to health and Knowledge through education is vital as a ground

Copyright (C2021 Nayab Minhaj

DOI: https://doi.org/10.37256/ges.222021788

This is an open-access article distributed under a CC BY license

(Creative Commons Attribution 4.0 International License)

https://creativecommons.org/licenses/by/4.0/ 
in increasing the frontier of knowledge; nevertheless, both indexes of health and education are basic enough to the broader notion and thus to expand human skills and capabilities that lie in the cycle of the common meaning of human development (Tadora, 2011).

Pakistan, since the nineteenth century, in the quest to develop her economy adopted several planning strategies but emphasized most on the formation of material and physical capital as possible ways of determining capital development among humans. Nevertheless, in the 1990s once global organization investment in human formation started through the establishment of the United Nations Development Programme which commenced as a business, producing the human development report once a year, the capital development among humans is seen as a direct way to start of the trend of development by gaining reasonable ground in many nations worldwide which includes Pakistan (Rob, 2004) in 1999, the United Nations Development Programme impact assessment on Pakistan reveals that the country is overheated from the crumbs of poverty due to underdevelopment (Schultz, 1993), this assessment shows that no beneficial policy and programme have been made by the government to reduce the trend of poverty in the country.

Capital development among humans in Pakistan is severely underdeveloped due to most planning in Pakistan is geared toward the formation of capital mainly for development and growth by neglecting the other vital gains of capital formation among humans. Pakistan is strongly committed to the programmes of constructing roads, dams, powerhouses, and factories pertaining to light and heavy industries, hospitals, schools, colleges, and a host of other activities with development planning. For this, they have various professions. If there's a lack of this unique style of capital formation, it can be said that physical capital cannot be productive, or utilized at this point. As a result, machines break down and wear out soon, material and components are wasted and production falls. Thus, the failure of capital development among humans to meet or grow at the rate of physical capital has been responsible for the decrease in human capital development in Pakistan. Hence, there is a crucial role played by human capital investment in Pakistan because it needs to staff new and expanding government services, develop communication means, and continue industrialization, building a variable health and education system in Pakistan. It is evident that capital development among humans is highly required for meaningful growth to be experienced in the Pakistan economy. The main goal of Pakistan has always been ensuring that there is a vehicle within which the Pakistan economy can be stimulated again through using her endowed resources into production and making the domestic economy attend its optimal points of growth combined with a low level of output and human development drive with the country where the financial condition is not interrupted by any means of intervention either by the government of by market conditions. From studies and implications gathered it's been observed that the level of education in Pakistan is at its reduced form, seen in the area of workers using of most recent technological equipment and others machine which show improvement in their marginal rate of substitution, the evidence shows that its leads to reduced income, reduced saving and reduced investment and maintaining a wide level of consumption thus leading to low growth in the economy. It is in light of the above that study seeks to investigate the implication of human capital in Pakistan with a measure of extending her growth experienced in the economy. Upon which certain research questions will be highlighted as does human capital have any impact on the growth of the Pakistan economy? Is there any significant far-reaching effect between the underlying subject matter of discussion in Pakistan? The paper shall then be divided into various sections as the literature review, Methodology adopted and findings from the study shall be discussed and policy recommendations drew out from the study.

\section{Literature review}

\subsection{The concept of human capital development}

Capital development among humans has been regarded as a vital factor in the growth process of countries that is being bent on achieving a sustainable economy. Economical development is the macroeconomic objectives of nations developing, emerging, and developed. No country in the world has ever gained sustained economic goals with farreaching development without substantial capital investment in the economy. Pakistan and other countries are rated as "less developed" by international standard and thus, Pakistan has grown with a goal to attain various aspects of economic differences in technical progress by enhancing economic capabilities. Capital development among humans is defined in various ways by the skills and capacity of the human resources of a country. The term capital development is seen as gaining, elevating humans through various means of skills, knowledge gathering, through which the economy 
attains its optimal points and the gains of the economy become favorable enough (Udo, 2009). It could further be explained as the attributes gained by workers by education, and training in experience, Mohsin (2005) noted that human capital is an investment placed in the sight to improves man's productive sense and abilities. Capital development is seen as a transformation from input into output. Thus, capital formations revolve around enhancing skills and abilities. Again, investment in health and education aims to enhance, stimulate humans into developmental drives. Jones (1996) noted that an investment in human capital formation tends to raises the gross national products of a country, thus leading to a low line of poverty and support to the frontier of knowledge.

Knowledge gathering reduces inequality as discussed. In view of this, prompted Hanushek (2013) to state "by closing the gap in physical input success is seen to be attain in development of capital and also closing the gap in knowledge". In the development capital of a nation, health and education are essential. As noted by Mankiw (1992) to affect human abilities and strength it's vital to consider the input of health, education advances, technical progress, and social investments. The justification for health and education as the most essential for capital development is that most of what we call consumption to constitute an investment opportunity in capital development and direct expenditure, healthcare, education, and internal migration to take the gains of better job opportunities are examples. Capital development among humans is seen as a method of exploiting the rising quantity needs of one that has the abilities, training, and knowledge sense necessary for development and growth within an economic unit. The gains from these investments in human capital are an effective one cutting across the wellbeing, knowledge, skill, and training of individuals thus such an individual is productive in all tiers of engagements within her economy. Capital development opined by economists as a prerequisite for countries to attain certain trends of changes in their political sense and the generality of the economy, based on the fact that these advancements will indeed increase tiers with most advanced nations of the world (Garba, 2002). Upgrading the nature of human capital through foreign aid in Pakistan for 19802016, by applying Johansen cointegration and Granger causality is inspected (Ali et al., 2012). The result suggested single direction causality from human capital and foreign aid and the presence of a two-way causal relationship among human capital and HDI. Further, (Awan \& Kamran, 2017) distinguished the relationship between human resources improvement and economic growth in Pakistan by applying time-arrangement information for the period (1985 to 2014). The result suggested that human capital development plays a crucial role in economic growth. And, Kazmi et al. (2017) examined the effect of human capital development on the economic growth of Pakistan by using time series data for the period 1992 to 2014. The obtained result presents the strongest evidence for the relationship between human resources and economic growth. Moreover, Afridi (2016) investigated the role of human capital development to increase productivity which could help in economic progress in Pakistan, and highlight the fact that Pakistan ranking was dropping in the human capital index. The result suggested that education and health sectors need attention to achieve the target of economic growth. In addition, Jalil and Idrees (2013) investigated the role of education to boost human capital development and the influence of the GDP in Pakistan for the period from 1960 to 2010. The results empirically support the education region has vital for significant growth and positively related to economic growth. Ali et al. (2012) examined the role of human capital formation in economic growth in Pakistan from 1972 to 2011 through tine series data. The results exhibit that human capital development is to be considered essential for the economic growth of Pakistan. As well, the role of human capital is analyzed by Asghar et al. (2012) in Pakistan's economic growth from 1974 to 2009 by using time series data, the results prompt that human capital highly associated with economic growth. Correspondingly, Khattak and Khan (2012) appreciated the education sector among factors studied to development of human capital for economic growth in the perspective of Pakistan during 1971-2008. The study further highlights the fact that development in the education sector is positively related to economic growth. Furthermore, some analysis offers a different impression as according to Osiobe (2020). The notion of rising per capita public spending in human resources is considered controversial by most economists. Education has not been expanded. As result suggested that education growth in some areas has not ensured better economic conditions. Moreover, it is noted that resources that constitute human capital mostly gain from large economies of scale of nations and their strength. These inputs involve around all factor input of production channeled in tapped the untapped resources for the purpose of growing the economy. As noted by Galbraith (2011), the importance of capital development in Pakistan, noted that Pakistan has to be competitive enough in the face of other new countries' economic in the order to keep a national frontier and not represent hostage to materials in humans and capital flows. Again, noted that the main problem facing by Pakistan in this new era development and output building of the Pakistan economy from this statement, apparently to note that 
capital development is very imperative for the growth of an economy.

\subsection{Test and error correction model by Johansen}

Following unit tip studies, Johansen's cointegration experiment was conducted (Johansen and Juselius, 1990) and the Error Correction Model (ECM) was evaluated. In order to assess the velocity at which the dependent variable returned to equilibrium following a shift in independent variables an error correction system was created (ECM) (Banerjee et al., 2011). The long-term relationship between variables covered in the model was however a prerequisite for developing an ECM (1). Two kinds of the Johansen experiment, one with mention and one with its own value were defined. The null hypothesis of the rule test shows that the cointegrating matrix is smaller than or equal to $\mathrm{r}$, while the null hypothesis of an eigenvalue test is $r$. When the sample statistics are higher than the critical value, the null hypothesis is dismissed. If the null hypothesis is refused, the variables in the model are cointegrated and therefore verified as having a long-run relationship (Sjö, 2008).

\section{Methodology}

The study looks at the production of human resources and economic growth in Pakistan. Thus, this paper shall follow some form of calculation in the paper which is primarily used to determine the study functionality of different underlying hypotheses, such as the usage for endogenous growth theory, which notes that economic growth is essentially a result of endogenous, not external, powers. Endogenous growth theory indicates that human capital, innovation, and knowledge investments are an important factor in economic growth and impact guiding the study making a hypothetical expression of Government Expenditure on Health (GEH) and Government Expenditure on Education (GEE) on Nominal Gross Domestic Product (GDP) at the current price upon which time-variant scopes shall be used.

The hypothesis had been stated with the view of ascertaining the significant nexus of human capital development and Pakistan's economic growth. The functional form of the expression is given below.

$$
\mathrm{GDP}=\mathrm{F}(\mathrm{GEH}, \mathrm{GEE})
$$

Equation 1 reads that Gross Domestic Product is a function of expenditure by the government on health and education. In order to capture the influence of the stochastic or random variable, the equation is explicitly transformed as

$$
\mathrm{GDP}=\beta_{0}+\beta_{1} \mathrm{GEH}_{\mathrm{t}}+\beta_{2} \mathrm{GEE}_{\mathrm{t}}+\mathrm{U}_{\mathrm{t}}
$$

where:

GDP $=$ Gross Domestic Product

GEH $=$ Government Expenditure on Health

GEE $=$ Government Expenditure on Education

By using views for estimation, entering the dependent variables as well as explanatory variables in the equation specification. Then, we estimate coefficients and develop the hypothesis that either notes that human capital has an effect on economic development. H0 explains that there is no connection between variable (no cointegration) while H1 indicates that $\mathrm{H} 0$ is not valid, which means the meaningful association between variables exists.

$$
\begin{gathered}
\mathrm{H} 0: \beta 0=\beta 1=\beta 2=0 \text { (no cointegration) } \\
\mathrm{H} 1: \beta 0 \neq \beta 1 \neq \beta 2 \neq 0(\mathrm{H} 0 \text { is not true })
\end{gathered}
$$

Data Sources: The data series of this paper are indictors of countries yearly report of the World Bank database for the period (1980 to 2016) through the World Development Index (WDI) for Pakistan. 


\section{Results and discussion}

The results from the study shall be discussed and analyzed in the quest of relating the facts and the underlying economic impact of the time-variant series adopted for the study thus various estimation procedure shall be used in conducting the measures of the influence of the subject thereby drafting out adjusted policy deductions, the place of stationarity shall be ascertained using the Augmented Dickey Fuller (ADF) test.

Table 1. ADF generalized least squares (GLS) unit root result test at level and first difference

\begin{tabular}{cccccccc}
\hline Test & Variables & \multicolumn{2}{c}{ At levels } & \multicolumn{2}{c}{ First differences } & Order & Remark \\
\hline \multirow{4}{*}{ ADF } & & T-statistic & Critical & T-statistic & Critical & & \\
& GDP & 0.492024 & -3.548490 & -5.524144 & -3.552973 & $1(1)$ & Stationary \\
& GEE & -1.608138 & -3.548490 & -5.397795 & -3.552973 & $1(1)$ & Stationary \\
& GEH & -2.113507 & -3.548490 & -7.177153 & 3.552973 & $1(1)$ & Stationary \\
\hline
\end{tabular}

Source: Researcher's compilation from E-view (version 10.0)

Evidenced results from the Unit roots show that all variables satisfy the random walk process given that its mean and moments are adjusted to time as the first difference hence given this underlying assumption the entire variable is ordered in the same cointegration of order i(1). However, a need to check the analytical influence of the model as determined.

Table 2. Johansen cointegration test

\begin{tabular}{ccccc}
\hline & \multicolumn{2}{c}{ Unrestricted cointegration rank test (trace) } & & Prob \\
\cline { 2 - 5 } Hypothesized No. of CE(s) & Eigenvalue & Trace statistic & 0.05 Critical value & 0.0000 \\
\hline None * & 0.890991 & 114.4399 & 29.79707 & 0.0000 \\
At most 1 * & 0.662632 & 41.30115 & 15.49471 & 0.0196 \\
At most 2 & 0.152079 & 5.443948 & 3.841466 & \\
\hline
\end{tabular}

Source: Researcher's compilation from E-view (version 10.0)

Table 3. Johansen coIntegration test

\begin{tabular}{ccccc}
\hline & \multicolumn{2}{c}{ Unrestricted cointegration rank test (maximum eigenvalue) } & Prob.** \\
\cline { 2 - 5 } Hypothesized No. of CE(s) & Eigenvalue & Max-Eigen statistic & 0.05 Critical value & 0.0000 \\
\hline None * & 0.890991 & 73.13880 & 21.13162 & 0.0000 \\
At most 1 * & 0.662632 & 35.85720 & 14.26460 & 0.0196 \\
At most 2* & 0.152079 & 5.443948 & 3.841466 & \\
\hline
\end{tabular}

Source: Researcher's compilation from E-view (version 10.0)

From the above tables, the null hypothesis of no cointegration for $r>0$ in the model was rejected in both the trace statistics. The statistical values of these tests were greater than their critical values. However, the null hypothesis of no cointegration, that is $r \leq 2$ and $r<1$, could not be rejected in both the trace statistics, because their values were less than the critical values. This indicates that there are two cointegrating equations among the variables. The implication of this result is that a long-run equilibrium relationship exists between gross domestic product (GDP) and the human capital 
development variables used in the model. There is, therefore, a long term effect between the variants used in Pakistan within the period under study.

Table 4. Vector error correction model (VECM)

\begin{tabular}{|c|c|c|c|c|c|}
\hline \multirow[b]{2}{*}{ Variable } & \multicolumn{3}{|c|}{ Dependent Variable: Difference of Log GDP: D (LGDP) } & \multirow[b]{2}{*}{ P-value } & \multirow[b]{2}{*}{ Remarks } \\
\hline & Coefficient & Std. Error & T-statistic & & \\
\hline $\operatorname{ECM}(-1)$ & -0.406264 & 0.002599 & -2.410333 & 0.0228 & Accept \\
\hline GDP(-1) & 0.184543 & 0.180964 & 1.019778 & 0.3166 & Reject \\
\hline GEE(-1) & 51.77684 & 46.96773 & 1.102392 & 0.2797 & Reject \\
\hline GEH(-1) & -138.7579 & 81.87525 & -1.694748 & 0.1012 & Reject \\
\hline \multirow[t]{2}{*}{$\mathrm{C}$} & 3119.503 & 1111.389 & 2.806850 & 0.0090 & Reject \\
\hline & \multicolumn{3}{|c|}{ Reliability Test } & \multirow{2}{*}{\multicolumn{2}{|c|}{ Durbin-watson }} \\
\hline R-squared & Adj-R2 & F-statistics & Prob (F-stat) & & \\
\hline 0.865296 & 0.760338 & 4.527647 & 0.002947 & \multicolumn{2}{|c|}{2.279594} \\
\hline
\end{tabular}

Source: Researcher`s compilation from E-view (version 10.0)

From the estimated result above the value of the (c) is 0.184543 which shows other variant held fixed (GDP) increased by 0.184543 units. The coefficient of Government Expenditure on Education (-1) is 51.7768 implying that there is a positive relationship between government expenditure on education and gross domestic product such that a change in Government expenditure on education will have about over $51.7 \%$ increase in GDP. Similarly, the coefficient of Government Expenditure on Health (-1) is -138.7579 implying that there is a negative relationship between expenditure on health and gross domestic product such that a change in government expenditure on health brought about $138 \%$ decrease in GDP i.e. economic growth, as at the year under review. Results reveal that there is a negative GDPGEH relationship creating inefficient government health expenditure. This indicates that public health expenditure does not trigger change in GDP, which is a significant variable in health.

It was revealed that $\mathrm{R}^{2}$ is $86 \%$. This maintains a good best fit in the regression accounting for the dependent variable while the remaining $14 \%$ was due to disturbance or error term e.g. economy meltdown, low-productivity, low profitability, etc. thus, R-squared of two variables in a model remains unchanged hence the R-squared determines the proportion of the variance between the dependent variables and independent variables.

The overall level of significance shows that the entire influence is positive by 4.52 is greater than F-tab. The joint test explains further that all applied endogenous series significant to a Gross domestic product from the year under review. Thus, the hypothesis which states that human capital development has no positive and significant influence on economic growth in Pakistan is rejected. Therefore, the alternative is accepted that human capital development has a positive and significant influence on economic growth in Pakistan from the estimated model

The value of the Durbin Watson of 2.24 shows the absence of autocorrelation which makes the estimate unbiased, consistent, and reliable for policy formulation. Error term shows that there is a speed of adjustment of $40 \%$ within the short and long equilibrium.

\section{Conclusion and policy recommendation}

The implication of the results as gotten from the analysis above, it can be seen that the joint influence of government expenditure of health and education in Pakistan shows that from the point of interest of 1981 to the reviewed time log of 2017 there have been lots of improvement in government index of expenditure in the areas of education and health which are a captivating factor for human capital development to influence the entire economy of Pakistan, we can therefore assert that the government of Pakistan have careful utilized capital spending in these two 
sectors as crucial to capital development within the populace this is also to say that lots more ought to be done in the aspect of the development of skilled manpower and housing the primary healthcare needs of the citizen once these is enhanced the economic is been stimulated to produce more output. Upon this basis that it's therefore recommended that government continues investment in the area of human capital development through adequate and functional healthcare sector and enabling infrastructure in the education sector for optimal efficiency and thus promoting development and growth of the Pakistan economy. Further, it is necessary for the government to examine real output losses due to disease, injury, and death and potential substitution costs. To measure these output losses, the value-added loss due to decreased efficiency must be estimated. It is the responsibility of the government to support education and health through training and awareness programs and empower the needy with financial assistance.

\section{References}

Ali, S., Sharif Chaudhry, I., \& Farooq, F. (2012). Human capital formation and economic growth in Pakistan. Pakistan Journal of Social Sciences (PJSS), 32(1).

Afridi, A. H. (2016). Human capital and economic growth of Pakistan. Business \& Economic Review, 8(1), 77-86.

Asghar, N., Awan, A., \& Rehman, H. (2012). Human capital and economic growth in Pakistan: A cointegration and causality analysis. International Journal of Economics and Finance, 4(4), 135-147.

Awan, A. G., \& Kamrun, M. (2017). Impact of human capital development on Pakistan economic growth. Global Journal of Management Social Humanities, 3(3), 418-439.

Banerjee, A., Marcellino, M., \& Masten, I. (2014). Forecasting with factor-augmented error correction models. International Journal of Forecasting, 30(3), 589-612.

Galbraith, I. (2011). The New Industrial State Pengium. Harmondsworth: Adventure Publishers.

Garba, P. (2002). Human capital formation, utilization and the development of Nigeria. Annual Conference of the Nigeria Economic Society (pp. 58-70). Ibadan: Nigeria Economic Society.

Hanushek, E. (2013). Economic growth in developing countries: The role of human capital. Economics of Education, $37,204-212$.

Jalil, A., \& Idrees, M. (2013). Modeling the impact of education on the economic growth: Evidence from aggregated and disaggregated time series data of Pakistan. Economic Modelling, 31, 383-388.

Johansen, S., \& Juselius, K. (1990). Maximum likelihood estimation and inference on cointegration-with appucations to the demand for money. Oxford Bulletin of Economics and statistics, 52(2), 169-210.

Jones, C. (1996). Human Capital Ideas and Economic Growth. Palgal: Mandragone International Economic Seminar on Finance.

Kazmi, S. M., Ali, K., \& Ali, G. (2017, October). Impact of human capital on economic growth: Evidence from Pakistan. Sustainable Development Policy Institute. http://hdl.handle.net/11540/7744.

Khattak, N. U. R. K., Khan, J., Khan, I., \& Tariq, M. (2012). An analysis of the demand for higher education in Pakistan with special reference to Khyber Pakhtunkhwa. City University Research Journal, 3(1).

Mankiw, N. (1992). A contribution to the empirics of economic growth. The Quarterly Journal of Economics, 10(2), 158-167.

Mohsin, K. (2005). Human capital and economic growth in Pakistan. The Pakistan Development Review, 44(4), 455478.

Osiobe, E. U. (2020). Human capital, capital stock formation, and economic growth: A panel granger causality analysis. Journal of Economics and Business, 3(2).

Rob, A. (2004). The Impact Of Human Capital Formation And Economic Growth In Pakistan. Karachi: Office for official publications of the European Communities.

Sjö, B. (2008). Testing for unit roots and cointegration. Lectures in Modern Econometric Time series Analysis.

Schultz, T. (1993). The economic importance of human capital in modernization. Education Economics, 1(1), 13-19.

Tadora, F. S. (2011). Human resource development and economic growth in Bangladesh. European Journal of Business and Management, 5(7), 133-144.

Udo, H. (2009). Human capital development and economic growth evidence from Nigeria. International Journal of Development Studies, 4(3), 80-85. 